\begin{tabular}{|c|l|}
\hline Title & $\begin{array}{l}\text { The smart city as a common place for tourists and residents: A structural analysis of the determinants of urban } \\
\text { attractiveness }\end{array}$ \\
\hline Author(s) & Romao, Joao; Kourtit, Karima; Neuts, Bart; Nijkamp, Peter \\
\hline Citation & $\begin{array}{l}\text { Cities, 78, 67-75 } \\
\text { https://doi.org/10.1016/.cities.2017.11.007 }\end{array}$ \\
\hline Issue Date & 2018-08 \\
\hline Doc URL & http://hdl.handle.net/2115/79256 \\
\hline Rights & $\begin{array}{l}\text { O2017. This manuscript version is made available under the CC-BY-NC-ND 4.0 license } \\
\text { http://creativecommons.org/icenses/by-nc-nd/4.0/ }\end{array}$ \\
\hline Rights(URL) & http://creativecommons.org/icenses/by-nc-nd/4.0/ \\
\hline Type & article (author version) \\
\hline File Information & romao_cities.pdf \\
\hline
\end{tabular}

Instructions for use 
THE SMART CITY AS A COMMON PLACE FOR TOURISTS AND RESIDENTS: A STRUCTURAL ANALYSIS OF THE DETERMINANTS OF URBAN ATTRACTIVENESS

\author{
João Romão \\ University of Algarve, Portugal \\ joao_romao@me.com \\ Karima Kourtit \\ Royal Institute of Technology, Sweden; Adam Mickiewicz University, Poland \\ Bart Neuts \\ Auckland University of Technology, New Zealand \\ Peter Nijkamp \\ Tinbergen Institute, the Netherlands; Adam Mickiewicz University, Poland
}

This document corresponds to the accepted manuscript accepted for publication as:

Romão, J., Kourtit, K, Neuts, B., Nijkamp, P. (2017) The Smart City as a Common Place for Tourists and Residents: A Structural Analysis on the Determinants of Urban Attractiveness. Cities.

DOI: $10.1016 /$ j.cities.2017.11.007 


\title{
THE SMART CITY AS A COMMON PLACE FOR TOURISTS AND RESIDENTS: A STRUCTURAL ANALYSIS OF THE DETERMINANTS OF URBAN ATTRACTIVENESS
}

\begin{abstract}
This article presents a structural modeling analysis of the performance determinants of urban attractiveness, in terms of resident population and international tourism demand, in 40 global cities. The analysis focuses on the impacts of a diverse set of innovative drivers of urban value creation and sustainable solutions for city development (urban functions), which are collectively subsumed under the heading of 'sustainable smart city'. Recognizing that the dynamics and growth processes related to these urban functions may have different impacts on different types of stakeholders, potentially leading to the emergence of serious conflicts between guests/visitors and residents, we aim to derive model-based implications for urban and tourism management in the cities concerned in order to move towards the sustainable future city as 'a place 4 all'. The results of our latent growth curve model confirm the existence of different impacts of urban functions on visitors' and residents' attractiveness. Cultural dynamics appears to be a major determinant for attracting new residents and supporting a strong international tourism industry. From an economic perspective, purely economic strength (in terms of absolute growth) appears to enhance city attractiveness for residents, while the dynamics observed in research and development activities influences the quality of employment instead of being a direct driver of population growth. While the social aspects of sustainability (framed under the concept of livability) and the urban environment typically exert higher impacts on urban attractiveness, accessibility appears mostly relevant for visitors. Our analysis suggests an uneasy balance between livability, environment, and population and visitor volume and growth.
\end{abstract}

\section{Keywords:}

smart city; livability; sustainability; creative city; urban attractiveness; urban management performance 


\section{Introduction}

The unprecedented concentration of human population in urban settlements, as is witnessed in contemporary cities (containing nowadays more than $50 \%$ of the world population, and possibly reaching more than $70 \%$ by the mid- 21 st century) raises intriguing questions for sustainable urban management. Cities are faced with great challenges, in the context of new economic tendencies (e.g., the 'creative economy', with a rising importance of cultural values in urban production and consumption systems), demographic transformations (rural-urban and international migration, ageing societies), old and new environmental concerns (pollution and climate change), and far-reaching implications of new technologies (digital tools, with wide applications in different fields).

Modern cities are not only powerful engines for economic development and technological progress, but also - particularly in our age of global mass mobility - effective magnets for visitors (tourists and businessmen). Over recent decades, tourism - both domestic and international - has shown a sustained world-wide increase, becoming part of a new global lifestyle. More than half a century ago the founding father of central place theory, the German geographer Walter Christaller (1964), argued that tourists are driven by the goal of relaxing in undiscovered and unknown places characterized by unspoilt nature and absolute tranquility. Nowadays, however, with the mass emancipation of tourists, we observe the transition from a 'happy few' tourists to mass tourism in which large attractive cities play a dominant role (e.g., megalopolises, such as New York, London, Paris and Tokyo), but also medium-sized cities (such as Amsterdam, Stockholm and Geneva).

The present paper aims to map out in a quantitative manner the complex force field influencing urban attractiveness for visitors' and residents', as manifested in the urban profiles of 40 large, globally distributed cities. The selection of these global cities stems from a multi-annual comprehensive database produced by the Mori Memorial Foundation in Japan. This database contains about 70 carefully identified and empirically tested city indicators, aggregated on six main functional dimensions ('urban functions'), and offering a multidimensional profile of these cities. These six functional dimensions will be used in our econometric analysis - based on a latent growth curve 
model - of the above-mentioned complex force field of urban characteristics, population growth and international tourism flows.

By using this extensive dataset, including indicators that can assess the impacts of factors related to both contemporary smart economies (general economic conditions, cultural interaction, and research and development) and urban sustainability (livability, accessibility and environmental conditions), this work offers an original comprehensive analysis of the determinants of urban attractiveness for residents (measured by population growth) and tourists (measured by the evolution in numbers of international tourists) at a global or international level, offering new insights on the identification and measurement of the factors that determine the evolution and growth of a "sustainable smart city".

This topic has the focus of multiple analyses in the last years, mostly related to territorial marketing and place branding (see e.g., Kavaratzis, 2004; 2005), by adopting the theoretical framework offered by the concept of corporate branding (Ashworth \& Kavaratzis, 2009) and often taking into consideration the different perspectives of various stakeholders (see e.g., Merrilees, Miller \& Herington, 2012; García, Gómez \& Molina, 2012). These works are generally based on surveys expressing the preferences of different for specific cities (see e.g., Zenker, Knubben \& Beckmann, 2010), in which network analysis is often a common and useful technique to address this question (e.g. Seven, 2014). Although our work also takes into consideration the different impacts of the various "urban functions" of cities on two different agents (in particular, residents and tourists), the importance of those functions as determinants of urban attractiveness is estimated through its quantitative impacts on population growth and tourism dynamics (as described in the next Section), rather than being based on stated preferences, as is pursued in most applied works in this field.

The paper is organized as follows: A literature review and theoretical foundations for our analytical model are presented in the next section, while a detailed description of the data and variables to be used in the model is offered in the third section. Next, a latent growth curve model is developed in Section 4, along with a presentation of the main results obtained. These results will be interpreted and discussed in Section 5, with a view to policy and managerial implications for urban 
and tourism management in a 'smart city'. Finally, the main conclusions and a synthesis of findings will be presented.

\section{Review and methodological framework}

Creativity and the economy in the smart city

Our analysis focuses on the concept of a 'smart city', recently introduced and broadly utilized in contemporary urban studies, though often with different meanings. Although this concept was initially mostly linked to the utilization of (digital) technologies in urban management, our analysis assumes the broader perspective proposed by Caragliu, Del Bo and Nijkamp (2011, p. 70), that a city is smart "when investments in human and social capital and traditional (transport) and modern (ICT) communication infrastructure fuel sustainable economic growth and a high quality of life, with a wise management of natural resources, through participatory governance". This definition implies a multidimensional perspective, taking into consideration economic, social, environmental and technological issues, which will be included in our research, given the strategic relevance of smart cities for sustainable development, so as to prevent tourist destinations from a decline in their attractiveness or in their sustainable urban quality of life. The indicators used in our model for this urban impact assessment are largely in accordance with the general principles proposed by Balsas (2004) or, more recently, and at an institutional level, by the Organisation for Economic Cooperation and Development (OECD, 2015).

For the purposes of our analysis, the economic dynamics will be framed within the broader perspective of creative economies, assuming the rising importance of innovation and the integration of cultural values into the production and consumption systems in contemporary economies (CurridHalkett \& Scott, 2013). In this context, cities play a central economic role, due to the agglomeration effects related to knowledge externalities arising from the self-reinforcing concentration of creative activities in urban areas, broadly documented in the literature (see, e.g., Arribas-Bel, Kourtit, \& Nijkamp, 2016), including the analysis of emergent social conflicts related to the new economic dynamics and societal transformations (see e.g., Scott, 2007; Sassen, 2010; Florida, 2017). Thus, 
indicators related to cultural or R\&D activities will also be taken into account in our study, both as central elements of urban socio-economics and as potential determinants of urban attractiveness.

In this context, it is noteworthy to observe that a significant part of studies on city attractiveness focuses on the urban factors which appear to exert a larger influence on the ability to attract a creative population, in accordance with the contemporary tendencies in global economies, as witnessed, among others, by Zenker (2009), Zenker, Eggers \& Farsky (2013) for 15 large German cities, with a special focus on the "competition" between Hamburg and Berlin, or by De Noni, Orsi \& Zanderighi (2014) for the specific case of Milan. It is also important to observe that this process of attraction of a new and creative urban population is not free of potential social and urban problems, as recently noted by Florida (2017) in his study on 'urban crisis'.

\section{Livability, accessibility and sustainability}

Other important aspects in the analysis of smart cities - with clear impacts on the quality of life in urban centers - are the environment (pollution, air quality, water quality, $\mathrm{CO} 2$ emissions, green areas, balanced landscapes, etc.); accessibility and mobility (within the city, but also related to its connectivity to other national or international urban centers); and livability (including aspects related to health care, working environment, safety or cost of living). Despite different interpretations and utilizations of the concept of livability in the recent literature, there is a general consensus about the importance of measuring the quality of life in its multiple dimensions, including social aspects (Ruth \& Franklin, 2014; Lloyd, Fullagar, \& Reid, 2016) or intangible factors related to the urban environment (Kashef, 2016). For the purposes of our analysis, these aspects will be framed within the concept of sustainability, including elements related to the ecological and social characteristics of cities, while their effective impact on the attractiveness of cities to people will be analyzed and measured as well.

Similar to the concept of livability, the idea of sustainability has been used with different meanings in the literature over recent decades. In fact, as stressed by Jong, Joss, Schraven, Zhan and Weijnen (2015), a multitude of concepts - including sustainable, low-carbon, smart, resilient or knowledge cities - have been used recently, with different conceptual formalizations, but generally 
aimed at improving the living conditions and competitiveness of urban environments. These authors point out that sustainability is often linked to environmentally-oriented concepts (eco, green or lowcarbon), while 'smart' is more used when analyzing cognitive processes of city modernization.

\section{Sustainable smart city}

The conceptual framework adopted in our study follows the concept of "Sustainable Smart Cities" recently proposed by Ahvenniemi, Huovila, Pinto-Seppä and Airaksinen (2017); the sustainability concept is more often used to assess environmental questions, while the smartness (or creativity) concept is more closely connected to the role of technologies within the urban context, although both of them aim to improve the socio-economic development of urban areas. Thus, we identify here two broad areas of analysis (smartness/creativity - addressing the modernization of urban economies - and sustainability - addressing social and environmental conditions) in order to analyze the (rise in) attractiveness of contemporary cities in a sustainable and smart urban context (Figure 1).

These two broad concepts (creativity and sustainability), which are at the core of the definition of a contemporary smart (sometimes also called 'intelligent') city, can also act as attractors or magnets for visitors, as well as impacting the dynamics of the resident population. Over recent decades, tourism has experienced continuous growth related to a rise in people's leisure time and discretionary income, along with their increased awareness of the importance of knowledge and cultural interaction for personal and commercial development. This growth has highlighted, worldwide, the role of cities in tourism development, as they offer diverse packages of tourism products and services for visitors who vary in characteristics, motivations and behaviors (Mazanek, 2010).

\section{Urban tourism and creativity}

The creative elements prevailing in cities (innovation, cultural dynamics and interaction, artistic production, knowledge exchange, lifestyles, etc.) have received renewed attention in recent years, enriching the scope of the analysis of cultural heritage and its relationship with local economic development (see, e.g., Fusco Girard \& Nijkamp, 2009; Riganti, 2009). On the other hand, it should also be noted that diverse types of cultural heritage and creative activities exert different impacts on 
the motivation and satisfaction of different tourists within a destination (Romão, Neuts, Nijkamp, \& van Leeuwen, 2015a) and that the impact of the same cultural heritage can also differ between destinations (Romão, van Leeuwen, Neuts, \& Nijkamp, 2015b).

Urban mass tourism is usually driven by a varied portfolio of tourism attractions and services geared towards the interests and preferences of distinct groups of visitors. In other words, tourism is a place-based activity which is co-determined by the information-based and knowledge-based attitudes of these visitors. In general, urban mass tourism is characterized by three features (Cohen, 1972; Yiannakis \& Gibson, 1992; Butler, 1993; Coccossis \& Nijkamp 1995; Coccossis, 1996): coterminality (various forms of direct and indirect interactivity exist between the productivity unit - the city - and the client); spatiality (consumption, production and supply of tourism services occur usually in the same place); and temporality (consumption and production of tourist services normally take place at the same time).

Consequently, tourism in big cities is based on a permanent interaction between suppliers and clients. And therefore, tourism destinations become multi-product areas for multi-segment markets; they are even increasingly turning into repositories of information for mobile clients. The combination of these characteristics with the importance of cultural activities and heritage enhances the potential for the implementation of place-based and knowledge-based innovation strategies and practices in tourism. The intense development of information and communication technologies and their systematic application in tourism services have led to a real transformation of this sector over recent decades (Law, 2006; Sigala, Mich \& Murphy, 2008). This has increased the interaction between consumers and producers and led to the concept of the 'co-creation' of tourism destinations (Sfandla \& Björk, 2013), through permanent collaborative processes (Sigala, 2009) and the rising importance of tourists as creators of images of tourism destinations, and through the multimedia contents produced and shared in social networks (Mansson, 2011).

In the same vein, Boes, Buhalis and Inversini (2016) define a smart tourism destination as a complex ecosystem relying on processes of 'co-opetition' (cooperative competition) between different agents who compete for tourists while simultaneously cooperating to achieve a smart management and effective promotion of the tourism area concerned. These authors identify three levels of interaction 
characterizing the smartness of a destination: ICT, people and leadership based on participatory governance; relations between economic, social and technological actors; and different dimensions of innovation based on territorial resources. Nevertheless, a smart urban tourism development must also take into consideration the cumulative use of urban resources by tourists and residents, the joint competition for scarce public spaces, the potential overuse of facilities and infrastructures, possible inflationary processes, and an eventual distortion of local identities related to the commodification of cultural practices.

\section{Potential tensions between residents and tourists in the city}

The fast and intense development of urban tourism over recent decades is also creating new tensions and conflicts between local residents and visitors, as witnessed by Colomb and Navy (2017), although the 'host-guest' conflict as a research topic has a long tradition in the tourism literature, starting already in the 1970 s, with the criticism of mass tourism development in coastal areas. The 'Irridex' (Index of Irritation) proposed by Doxey (1975) was a first attempt to systematize this association, by describing a path from "euphoria" to "antagonism" in the relationship between the local community and tourists; Wall and Mathieson (2006) describe this later as a trend from "euphoria" to "xenophobia". With the massification of city tourism, this conflict has been spread to many urban areas, while new analytical formulations have been developed for its analysis in terms of causes and effects (see, e.g., Bimonte \& Punzo, 2016).

Two types of negative externalities are a source of concern in the rapid development of mass tourism. First, there is the ecological disturbance caused by large volumes of visitors (e.g., environmental degradation, decline in local resources, disturbance of quiet areas). Secondly, we observe increasing conflicts between tourist interests/behaviors and the interests of local residents (e.g., in the form of the destruction of traditional lifestyles and cultures, overcrowded city centers and busy tourist attractions, tensions in the joint use of open public spaces and public amenities, etc.). The latter type of negative social externality has become an increasingly important concern in the development of local community attitudes to modern mass tourism. Conflicts abound in the shared use of public spaces and on the impact of tourists on community life and cultural heritage (e.g., in cities like Venice, 
Rome, Barcelona and Amsterdam), and it is foreseeable that the profound social implications of a mass influx of visitors will get a more prominent place on the tourism policy agenda. What is at stake here, is the protection or maintenance of the ecological, cultural and social self-identity of cities in the context of their historical, traditional, socio-economic, spatial and architectural profile. Clearly, the interaction between (foreign) visitors and local residents in many tourist destination cities is at best an uneasy relationship.

The United Nations World Tourism Organization (UNWTO, 2012) emphasizes the importance of diverse and flexible urban tourism products and services for contemporary tourism dynamics. According to this agency, potential positive contributions from tourism to urban areas relate to urban vitality and dynamism, new (though potentially conflictive) patterns and changes in the urban landscape, personal relations and connections, job creation, income, and support for the maintenance of urban infrastructures and public services. On the other hand, this organization also stresses that the dynamics require adequate management of the increasing number of tourists, ensuring quality of life and socio-economic benefits for the local population, control of the environmental impacts by developing appropriate development plans, and the implementation of participatory decision-making processes.

\section{Conceptual framework}

Against this background, the present paper aims - as mentioned - to analyse the attractiveness of urban areas for residents and tourists within the framework of a 'sustainable smart cities' concept, and to contribute to the relatively underdeveloped empirical analysis of the impacts and dynamics of tourism in contemporary cities. We follow the structure presented in Figure 1, which synthetizes the conceptual-theoretical framework of this study.

The "sustainable smart cities concept" is explained and measured through six function-specific indicators, broadly covering two main characteristics: creativity and sustainability. We hypothesize a direct effect of these six indicators on the dependent variables of population growth (H1) and international tourism demand (H2), both as measurement of the general city attractiveness. This analysis will allow us to assess and measure the different (and potentially conflicting) factors 
determining the attractiveness of the cities under analysis to residents and visitors. The complementarity or conflicting nature of these factors will be discussed as well, along with the consequent policy and managerial implications for contemporary metropolitan areas.

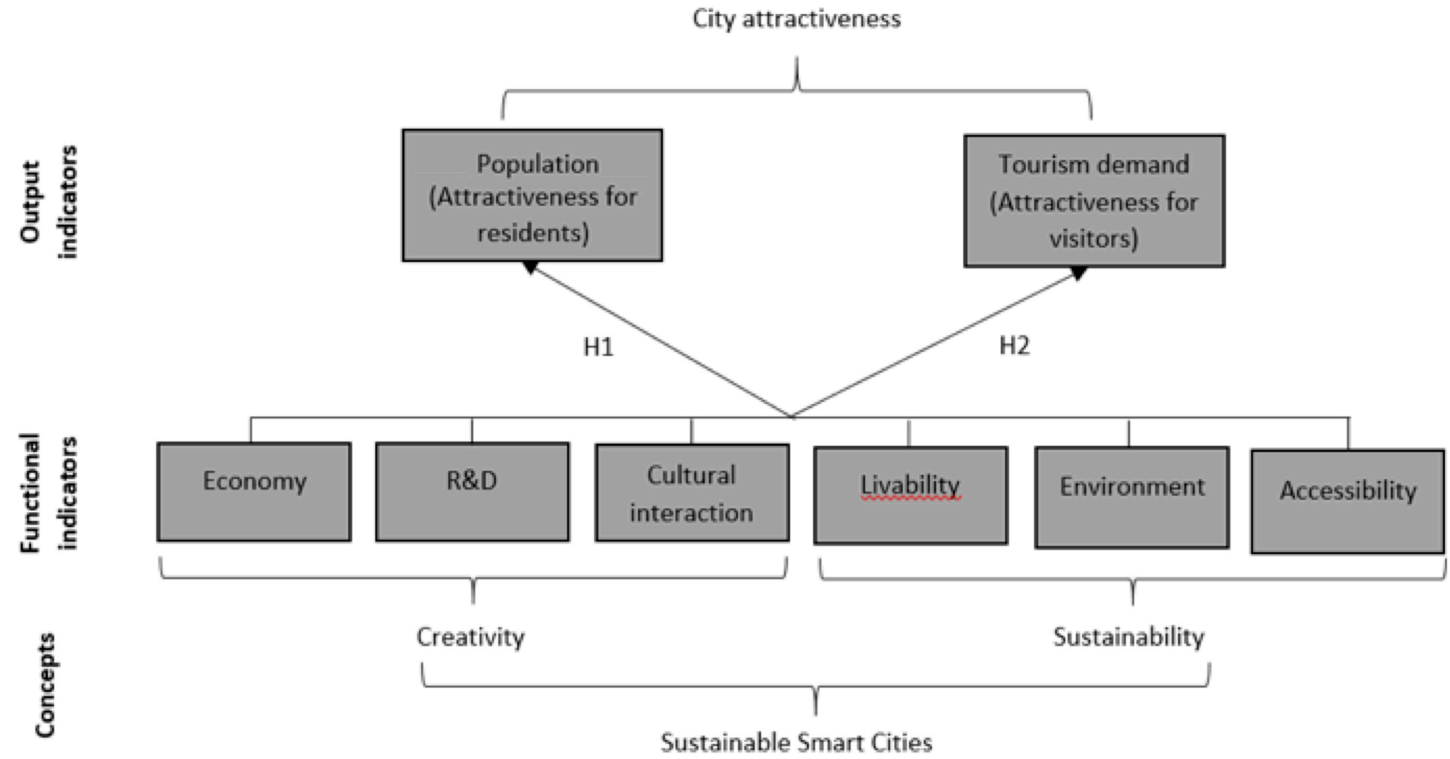

Figure 1. Structure of the conceptual-theoretical model for the analysis of local vs. visitors' interests

\section{Materials and methods}

\section{The Global Power City Index}

In order to empirically validate the conceptual model introduced in Figure 1, appropriate 'urban functions' indicators were collected from the Mori Memorial Foundation Global Power City Index (GPCI) for the five-year period, 2012-2016. The GPCI aims to evaluate major world cities in terms of global competitiveness by collecting and comparing reliable and objective quantitative data (see Mori Memorial Foundation, 2016). For the 2012-2016 period, 40 cities were included in the analysis (Table 1). These cities were chosen based on their presence in the top of existing, alternative city and competitiveness rankings, supplemented with large cities that fell outside of these criteria, but which were deemed by the Mori Memorial Foundation research committee to be appropriate for 
incorporation due to their position within the global economy and connectivity with a regional catchment area.

Table 1. The 40 cities in the dataset

\begin{tabular}{ll}
\hline Region & City \\
\hline Africa & Cairo \\
Asia & Bangkok, Beijing, Fukuoka, Hong Kong, Kuala \\
& Lumpur, Mumbai, Osaka, Seoul, Shanghai, \\
& Singapore, Taipei, Tokyo \\
Europe & Amsterdam, Barcelona, Berlin, Brussels, \\
& Copenhagen, Frankfurt, Geneva, Istanbul, \\
& London, Madrid, Milan, Moscow, Paris, \\
& Stockholm, Vienna, Zurich \\
Latin America & Mexico City, Sao Paulo \\
North America & Boston, Chicago, Los Angeles, New York, San \\
& Francisco, Toronto, Vancouver, Washington \\
& D.C. \\
Oceania & Sydney \\
\hline
\end{tabular}

Source: The Mori Memorial Foundation (2016)

For each of these cities, the GPCI data base collects 70 function-specific indicators (for a full overview, see The Mori Memorial Foundation, 2016, pp.6-7) that are aggregated into six functional scores by The Mori Memorial Foundation, reflecting the six main urban functions ('domains') introduced in Figure 1, namely: Economy, Research and Development $(R \& D)$, Cultural Interaction, Livability, Environment, and Accessibility. These six aggregated scores form a conceptually sound and convenient statistic for further use in our empirical model. Table 2 offers an overview of the 5 -year mean scores in the dataset for the six urban functions identified in the literature review as multidimensional aspects of the smart city concept, as well as the conceptual composition of the six urban functions.

Table 2. Yearly mean Global Power City Index score for function-specific urban function characteristics $(\mathrm{n}=40)$

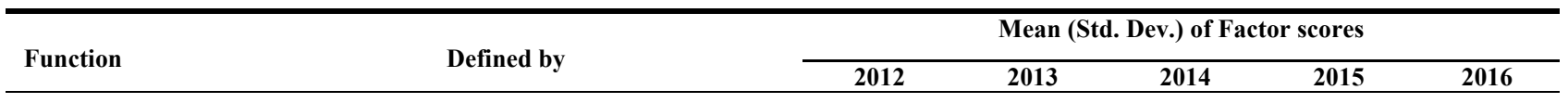




\begin{tabular}{|c|c|c|c|c|c|c|}
\hline Economy & $\begin{array}{l}\text { Market size, Market Attractiveness, Economic } \\
\text { Vitality, Human Capital, Business Environment, Ease } \\
\text { of Doing Business }\end{array}$ & $\begin{array}{c}201.1 \\
(54.051)\end{array}$ & $\begin{array}{c}203.4 \\
(52.351)\end{array}$ & $\begin{array}{c}210.4 \\
(51.576)\end{array}$ & $\begin{array}{c}204.3 \\
(53.485)\end{array}$ & $\begin{array}{c}203.9 \\
(50.646)\end{array}$ \\
\hline $\mathrm{R} \& \mathrm{D}$ & $\begin{array}{l}\text { Academic Resources, Research Background, } \\
\text { Research Achievement }\end{array}$ & $\begin{array}{c}65.8 \\
(43.847)\end{array}$ & $\begin{array}{c}65.8 \\
(46.993)\end{array}$ & $\begin{array}{c}63.8 \\
(45.869)\end{array}$ & $\begin{array}{c}68.1 \\
(48.831)\end{array}$ & $\begin{array}{c}68.1 \\
(46.877)\end{array}$ \\
\hline $\begin{array}{l}\text { Cultural } \\
\quad \text { Interaction }\end{array}$ & $\begin{array}{l}\text { Trendsetting Potential, Cultural Resources, Facilities } \\
\text { for Visitors, Attractiveness to Visitors, International } \\
\text { Interaction }\end{array}$ & $\begin{array}{c}117.8 \\
(65.885)\end{array}$ & $\begin{array}{c}117.2 \\
(64.315)\end{array}$ & $\begin{array}{c}118.1 \\
(63.391)\end{array}$ & $\begin{array}{c}111.7 \\
(62.767)\end{array}$ & $\begin{array}{c}123.2 \\
(61.269)\end{array}$ \\
\hline Livability & $\begin{array}{l}\text { Working Environment, Cost of Living, Security and } \\
\text { Safety, Well-Being, Ease of Living }\end{array}$ & $\begin{array}{c}246.2 \\
(33.202)\end{array}$ & $\begin{array}{c}236.1 \\
(36.593)\end{array}$ & $\begin{array}{c}241.8 \\
(34.845)\end{array}$ & $\begin{array}{c}260.0 \\
(33.650)\end{array}$ & $\begin{array}{c}281.8 \\
(34.033)\end{array}$ \\
\hline Environment & Ecology, Air Quality, Natural Environment & $\begin{array}{c}159.8 \\
(32.256)\end{array}$ & $\begin{array}{c}154.6 \\
(33.361)\end{array}$ & $\begin{array}{c}150.0 \\
(33.468)\end{array}$ & $\begin{array}{c}158.5 \\
(37.481)\end{array}$ & $\begin{array}{c}154.6 \\
(31.831)\end{array}$ \\
\hline Accessibility & $\begin{array}{l}\text { Int. Transp. Network, Int. Transp. Infrastructure, } \\
\text { Inner-City Transp. Service, Traffic Convenience }\end{array}$ & $\begin{array}{c}148.8 \\
(41.963)\end{array}$ & $\begin{array}{c}149.3 \\
(42.818)\end{array}$ & $\begin{array}{c}150.2 \\
(42.756)\end{array}$ & $\begin{array}{c}144.5 \\
(41.542)\end{array}$ & $\begin{array}{c}152.5 \\
(39.213)\end{array}$ \\
\hline
\end{tabular}

Source: The Mori Memorial Foundation (2012, 2013, 2014, 2015, 2016)

Since the six urban functions are considered to relate to the broad multidimensional concept of the smart city, Pearson correlation scores and multicollinearity diagnostics were calculated in order to test for sufficient discriminatory power between the functions and allow for a further multidimensional analysis. The Variance Inflation Factors (VIF) are all between 1 and 5, indicating a moderate, but not problematic, correlation between the factors.

Table 3. Pearson correlations and multicollinearity diagnostics for 2016

\begin{tabular}{|c|c|c|c|c|c|c|}
\hline & 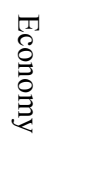 & $\ddot{E}$ & 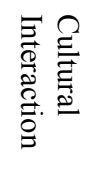 & 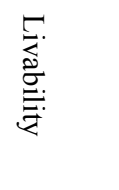 & 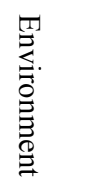 & 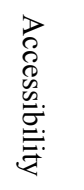 \\
\hline Economy & 1 & & & & & \\
\hline $\mathrm{R} \& \mathrm{D}$ & $.687 * *$ & 1 & & & & \\
\hline $\begin{array}{l}\text { Cultural } \\
\text { Interaction }\end{array}$ & $.540 * *$ & $.658 * *$ & 1 & & & \\
\hline Livability & .031 & -.067 & .041 & 1 & & \\
\hline Environment & .222 & .122 & .040 & $.431 * *$ & 1 & \\
\hline Accessibility & $.546^{* *}$ & $.494 * *$ & $.687 * *$ & .162 & .036 & 1 \\
\hline Tolerance & .448 & .398 & .392 & .739 & .735 & .453 \\
\hline VIF & 2.234 & 2.513 & 2.551 & 1.353 & 1.361 & 2.205 \\
\hline
\end{tabular}


Descriptive analysis: the compound annual growth rate

As a preliminary, descriptive step, the compound annual urban growth rate (CAGR) was calculated for the two dependent variables, Population growth and Tourism demand, through the formula:

$$
C A G R=\left(\frac{E V}{B V}\right)^{1 / n}-1
$$

where $\mathrm{EV}=$ end value of $2016, \mathrm{BV}=$ initial value of 2012, and $\mathrm{n}=$ time period. The mean CAGR for the population in our sample was 0.00981 (std. dev. $=0.01120$ ), while the CAGR for tourism demand showed more impressive growth figures at 0.04554 (std. dev. $=0.06286$ ). Figure 2 gives an overview of the spread of the CAGR scores. It can be seen from Figure 2 that population growth and tourism demand are mostly positive, with two strong positive outliers on the former, viz. Cairo (0.05422) and Bangkok (0.03867). A slightly negative compound annual growth rate of the population was more notable in European cities: in Berlin (-0.00057), Barcelona (-0.00124), Paris (-0.00250), and Madrid (0.00765), but also in Vancouver (-0.00062), and Seoul (-0.00445). In terms of growth in tourism demand, the highest growth rates are observed for the Asian region, in particularly Osaka (0.24999), Tokyo (0.23752), Fukuoka (0.16074) and Bangkok (0.13395), while the first European city with a high tourism growth is Istanbul, with a CAGR of 0.09825. Other cities in Europe, North America, Latin America and Oceania exhibit a slower positive growth rate over this five-year period. On the other end of the scale, Mumbai has shown a relatively strong decline (-0.06657), followed by Cairo (0.04975), Hong Kong (-0.03558), Beijing (-0.02821) and Shanghai (-0.01694). 


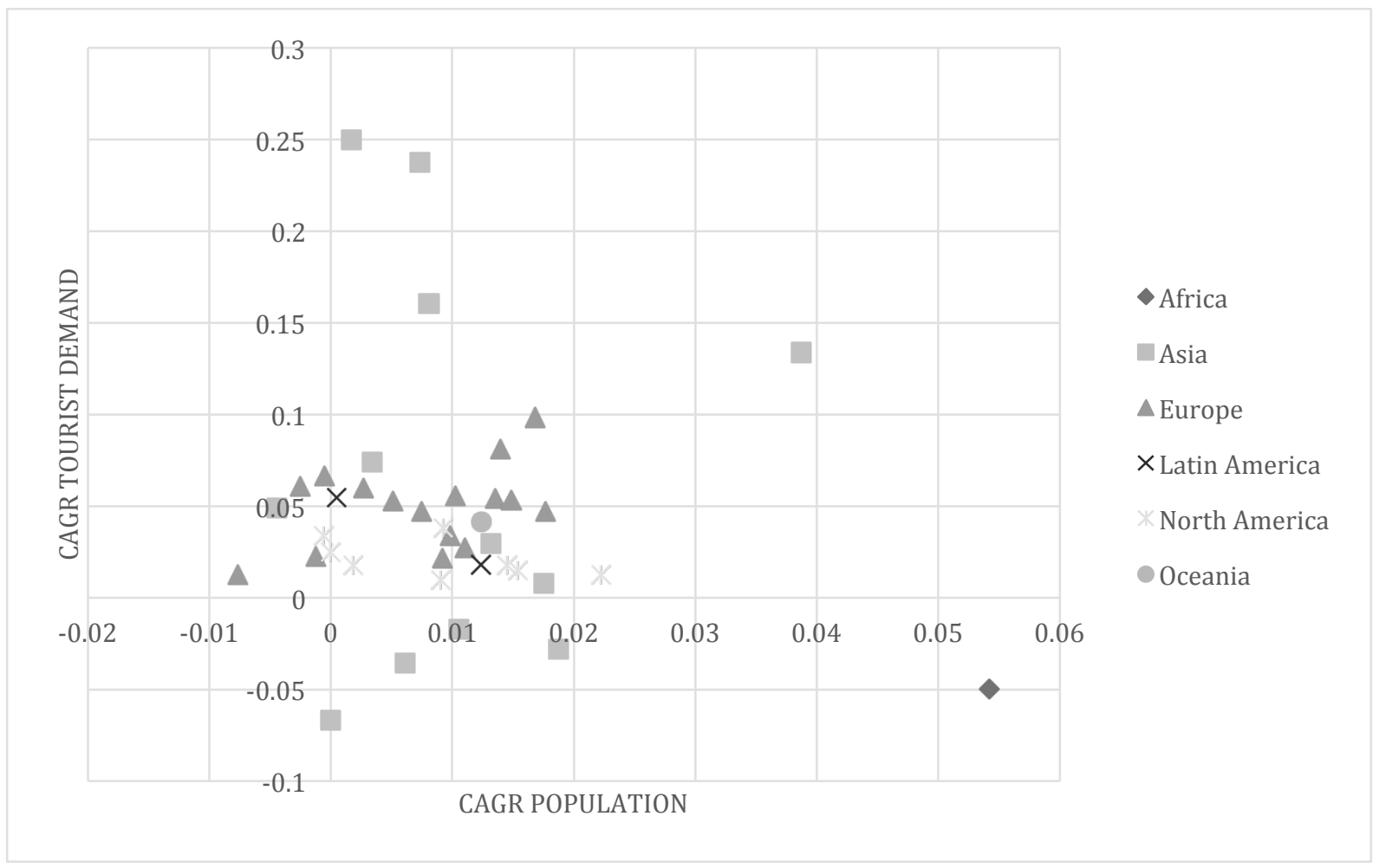

Figure 2. Spread of compound annual growth rates (CAGR) for 2012-2016

Analytical approach: latent growth curve modelling In order to analyze the effects of functional indicator scores on population growth and tourism demand over the 5-year period, a latent growth curve (LGC) model is used. LGC analysis is suitable for understanding a systematic change in panel design with longitudinal data and has the advantage of being a simple extension of the more general structural equation modeling framework (Berrington, Smith, \& Sturgis, 2006; Stoel, van den Wittenboer and Hox, 2004). Within a LGC model, the growth trajectory of longitudinal data is specified through two latent variables: the intercept and the slope. These latent variables are measured by the year-specific data points with loadings of the intercept factor constrained to 1 . The loadings of the slope factor can either be constrained to be equal to the rank of measurement occasion (i.e., 0 for year 1, 1 for year 2, 2 for year 3, etc.) for perceived linear growth (as shown in Figure 3), or alternatively, some of the factor loadings can be left unconstrained in order to allow for non-linear growth trajectories (Berrington et al., 2006).

In order to examine now predictors of the intercept and slope, exogenous variables (i.e., the function-specific scores of Table 2) were averaged and standardized in order to be included as time- 
constant variables. Although this is a simplification of reality in which function-specific scores do vary over the 5-year period, within the relatively short timeframe yearly changes are sufficiently small. Approaching these scores as time-invariant covariates allows us to identify their influence on variability in the starting point and rate of change (Curran, Obeidat, \& Losardo, 2010). Figure 3 gives a schematic overview of a typical conditional LGC model under linear specifications and accounting for two time-invariant covariates.

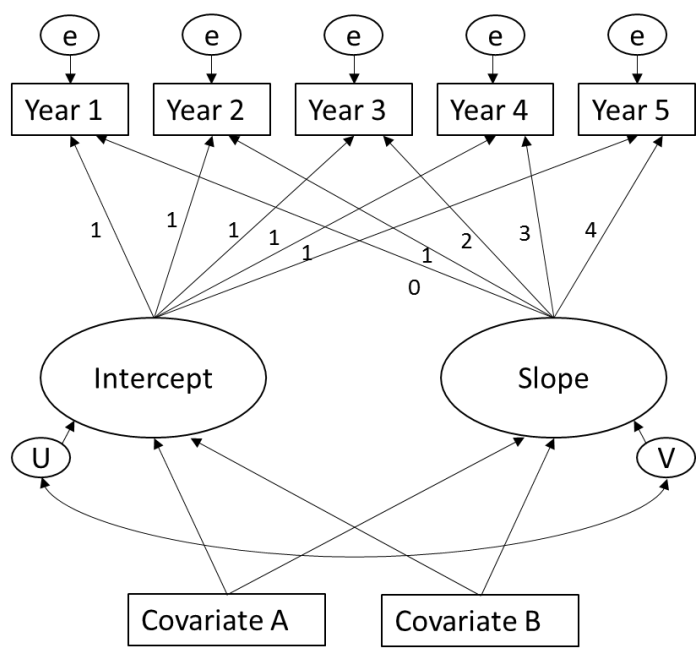

Figure 3. Schematic presentation of a typical linear latent growth curve model with two covariates

Note: $\mathrm{U}, \mathrm{V}=$ error terms of latent variables, $\mathrm{e}=$ error terms of indicator variables

$1,1,1,1,1=$ constant specification of factor loadings on intercept

$0,1,2,3,4=$ linear specification of factor loadings on slope

\section{Empirical results}

LGC models similar to the example shown in Figure 3 were constructed independently, due to limitations in sample size, for the two dependent variables: population growth and tourism demand, with the software package Amos 23.0. These models included 5-year data for population and tourism demand as measurement items, and six functional indicators as covariates. Linear models were tested as well as LGC models in which the slope factor loadings for the years 2015 and 2016 were left unconstrained. For both the population growth and the tourism demand model, the non-linear specification outperformed the linear model. Tables 4 (for population) and 5 (for tourism demand) give a concise and systematic overview of the relationships found in the non-linear LGC models. Various fit indices show a reasonable to good fit of the population model, with a Chi-square $(\mathrm{Df}=24)$ 
of 34.217 (p-value $=0.081$ ), a relative Chi-square of 1.426 , a CFI of 0.993 , and a standardized RMR of 0.0019 (see Hooper, Coughlan, \& Mullen, 2008). Similarly, the LGC model on tourism demand shows comparable and acceptable fit indices: a Chi-square $(\mathrm{Df}=21)$ of $29.855(\mathrm{p}$-value $=0.095)$, a relative Chi-square of 1.422, a CFI of 0.988 , and a standardized RMR of 0.0265 .

Table 4. Model estimates of the latent growth curve (LGC) model on population under maximum likelihood estimation

\begin{tabular}{|c|c|c|}
\hline & Estimate (S.E.) & P-value \\
\hline \multicolumn{3}{|l|}{ Intercepts } \\
\hline$<-$ Population intercept & $5.167 * * *(.545)$ & $<.001$ \\
\hline$<$ - Population slope & $.082 * * *(.015)$ & $<.001$ \\
\hline \multicolumn{3}{|c|}{ Unconstrained factor loadings of slope } \\
\hline <- Population 2015 & $2.631 * * *(.060)$ & $<.001$ \\
\hline <- Population 2016 & $3.247 * * *(.114)$ & $<.001$ \\
\hline \multicolumn{3}{|l|}{ Covariates } \\
\hline \multicolumn{3}{|l|}{ On intercept } \\
\hline$<-$ Economy & $3.218 * * *(.829)$ & $<.001$ \\
\hline$<-\mathrm{R} \& \mathrm{D}$ & $-2.517 * * *(.932)$ & .007 \\
\hline$<-$ Cultural Interaction & $1.631 *(.878)$ & .063 \\
\hline$<-$ Livability & $-1.240 *(.721)$ & .086 \\
\hline$<-$ Environment & $-3.150 * * *(.692)$ & $<.001$ \\
\hline$<-$ Accessibility & $-.275(.819)$ & .737 \\
\hline \multicolumn{3}{|l|}{ On slope } \\
\hline$<$ - Economy & $.078 * * *(.022)$ & $<.001$ \\
\hline$<-\mathrm{R} \& \mathrm{D}$ & $-.098 * * *(.025)$ & $<.001$ \\
\hline$<-$ Cultural Interaction & $.060 * * *(.023)$ & .008 \\
\hline$<$ - Livability & $-.056^{* * *}(.019)$ & .003 \\
\hline$<$ - Environment & $-.058 * * *(.018)$ & .001 \\
\hline$<-$ Accessibility & $-.018(.021)$ & .407 \\
\hline
\end{tabular}

Note: $0.01 * * *, 0.05^{* *}, 0.10^{*}$

First of all, the intercepts indicate a mean starting population of 5.167 (in millions) in our sample, although the variance of 11.599 (p-value <.001) indicates significant intercity differences. A positive average rate of change of .082 implies significant population growth over the 2012-2016 period, with a variance of .012 (p-value <.001) suggesting intercity differences in the speed of urbanization, similar to what was presented in Figure 2 on the analysis of the CAGR. Since the model 
was tested under non-normality assumptions, the unconstrained factor loadings on the slope-variable further inform us about model specifications. For linear growth to be achieved, values of 3 , for the population in 2015, and 4, for the population in 2016, would have been expected. Since we find slightly lower factor loadings, growth has apparently slowed down slightly in later years of the analysis. Furthermore, the intercept and slope are positively correlated (.270), which means that larger cities have a tendency to grow at a faster rate as well. In the top 5 of densely populated cities, only Mumbai showed a below average growth rate, with Shanghai, Beijing, Istanbul, and Moscow growing at an increased rate.

The covariate analysis indicates which factors contribute or detract from both the starting point intercept and the 5-year growth. There is a significant positive correlation between Economic strength (3.218) and the initial population estimate. On the other hand, Environmental quality (-3.150) and the state of Research and Development $(-2.517)$ seem to be negatively related to population size, the latter possibly related to the low score on research and development by megacities such as Mumbai, Mexico City, Sao Paulo and Cairo. Similarly, these are also regions that suffer from negative environmental circumstances and where environmental sustainability is more difficult to achieve, partly due to lower GDP per capita.

Two interactions positively influence population growth rate: the Economy (.078) and higher levels of Cultural Interaction (.060). Since Cultural Interaction includes variables of international visitation, cultural facilities, and conferences and events, it might imply that there is a correlation between qualitative visitor amenities and residential quality in terms of attracting new residents. There are, however, important negative effects on population growth to consider: Research and Development (-.098), Livability (-.05), and Environmental quality (-.058) all slow down the urban growth rate. It might look counterintuitive that cities with higher scores on Livability seem to exhibit a slower (or even declining) population growth. However, rather than indicating that an increase in Livability indicators leads to a less attractive living environment, this negative association can be ascribed to the fact that comparatively smaller cities in the database with a modest population growth (e.g. Vienna, Geneva, Zurich, Amsterdam, Copenhagen) score higher on the Livability dimension than a few major cities with excessively high population growth and lower Livability scores (e.g. Cairo, Bangkok, 
Beijing). The parameters of Research and Development and Environmental quality can be interpreted in much the same way. While it would be erroneous to assume that this combination of results might indicate limitations to urban size, above which cities no longer perform optimally in terms of creative sector investments and growth, and residential amenities, we argue, building on Camagni, Capello, and Caragliu (2013), that this could be an indication of a local disequilibrium between costs and benefits in these specific urban areas.

Table 5. Model estimates of the latent growth curve (LGC) model on tourism demand under maximum likelihood estimation

\begin{tabular}{lcc}
\hline & Estimate (S.E.) & P-value \\
\hline Intercepts & & \\
<- Tourism intercept & $4.313^{* * *}(.332)$ & $<.001$ \\
<- Tourism slope & $.064^{* *}(.026)$ & .016 \\
& & \\
Unconstrained factor loadings of slope & & \\
<- Tourists 2015 & $6.117^{* * *}(1.510)$ & $<.001$ \\
<- Tourists 2016 & $10.352^{* * *}(1.933)$ & $<.001$ \\
& & \\
Covariates & & \\
$\quad$ On intercept & $.485(.495)$ & .327 \\
$\quad<-$ Economy & $-.641(.560)$ & .252 \\
<- R\&D & $1.703^{* * *}(.520)$ & .001 \\
<- Cultural Interaction & $-.918^{* *}(.433)$ & .034 \\
<- Livability & $.370(.410)$ & .367 \\
<- Environment & $1.863^{* * *}(.486)$ & $<.001$ \\
<- Accessibility & & \\
On slope & $-.050(.030)$ & .103 \\
<- Economy & $.074^{* *}(.037)$ & .049 \\
$<-$ R\&D & $.005(.028)$ & .854 \\
<- Cultural Interaction & $.057^{* *}(.029)$ & .048 \\
<- Livability & $-.010(.022)$ & .666 \\
<- Environment & $.020(.027)$ & .445 \\
<- Accessibility & &
\end{tabular}

Note: $0.01 * * *, 0.05^{* *}, 0.10^{*}$

Our second model interprets the effects of urban functions on international tourism. The mean starting point for tourist arrivals equals 4.313 (in millions), with a non-significant variance of .510 (pvalue $=.748$ ) indicating that the 40 cities of the sample are less variable in terms of international 
tourists as they are on population size. A positive average rate of change of .064 implies significant growth in tourism over the 5-year sampling period, with a non-significant variance of .191 (p-value $=.069)$. We observe here a significant covariance of $.752(\mathrm{p}$-value $=.022)$ between intercept and slope, again indicating that cities with higher initial tourist demand are likely to grow at a faster rate. The unconstrained factor loadings further indicate that this growth is happening at an exponential, instead of linear, rate, with factor loadings of 6.117 and 10.352 .

The intercept is positively affected by Cultural Interaction (1.703) - a factor that already incorporates aspects of visitor attractiveness and facilities for visitors - and Accessibility scores (1.863). Similarly, it seems logical that cities with stronger international transport links - forming part of the Accessibility dimension - achieve higher international visitor numbers. One negative relationship between the visitor-intercept and urban functions concerns the Livability factor (-.918). Given the fact that Livability encompasses aspects of local price level, average house rent, and security and safety, the negative association can be supported by the extant literature on negative social externalities from tourism (e.g. Füller \& Michel, 2014; Alam \& Paramati, 2016; Gutiérrez, García-Palomares, Romanillos, \& Salas-Olmedo, 2017).

At the same time, however, positive effects of Livability (.057) on the slope variable indicate that Livability contributes to a faster growth of tourism. This might be related to the different indicator groups within the Livability concept: aspects related to the cost of living and security and safety might be influenced negatively by larger absolute tourism numbers (hence the negative effect found on the intercept), while other aspects such as general well-being and ease of living could constitute an attractive product for prospective tourists (hence the positive effect on contributing to visitor growth). Furthermore, there was a somewhat positive correlation with a city's score on Research and Development, possibly indicating that the academic environment can be a driver for cultural interaction and international tourist flows.

\section{Discussion and interpretation in a smart city context}

Within the context of smart or intelligent city strategies in a competitive globalized urban environment, a first logical and clear conclusion lies in the effect of a strong economic component on urban 
population. Cities with a well-functioning economy offer opportunities for current and new urbanites, and fuel city size and growth. Unsurprisingly, no effect is found between economic strength and tourism demand, with urban tourism being driven by very different factors (e.g. Romão et al. 2015a).

Besides the direct effect of the economy, the diversification of economic activities - in particular the Research and Development environment - is also primarily of interest to the resident population. In this case, the results of the LGC model indicate an inverse relationship with population growth and population size. This cannot be interpreted as a signal that Research and Development investments negatively impact the residential population though. Rather, it is an indication that for the cities in the Mori Memorial Foundation database, more modestly populated cities outperform the largest urban areas, linking it to discussions on sustainable growth. Furthermore, the effect of Research and Development is expected to relate more to educational level of the population than to population size per se. The Research and Development environment in a city will ultimately affect residential quality, by offering job opportunities and further positive externalities in the form of new start-ups which in itself can lead to gentrification and rising housing prices, therefore slowing down the growth rate of urban areas through lower and middle-class income groups (Florida, 2017). There appears to be also a notable link between Research and Development investment and tourism, potentially indicating some importance of business- and conference-related tourism trips in these cities.

Within a smart city context, the strong effect of Cultural Interaction is clearly confirmed, particularly in relation to visitors. Cities with strong scores on Cultural Interaction have confirmed themselves on the global stage as established, attractive destinations with above-average tourist numbers. The weaker link with the population intercept may be due to the way that the Cultural Interaction factor is constructed, in the Mori Memorial Foundation database, with a stronger focus on visitor facilities (e.g., number of international conferences, number of museums, number of hotels, number of visitors from abroad). Clearly, it is evident that residents profit equally from attraction factors such as attractiveness of shopping and dining, world heritage sites, museums, theatres and concert halls, and this is confirmed by the significant positive effect of Cultural Interaction on population growth, indicating that cities with stronger scores on Cultural Interaction are likely to grow at a faster rate. 
The results of our analysis further show the difficult balance of Livability in populous urban centers with a strong tourist demand. Livability is strongly associated with a favorable environment for residents, and creative industries alike, being measured through the working environment (e.g., working hours, employee satisfaction), as well as with the living environment (e.g., average house rent, price level, life expectancy, population density, variety of shops and restaurants). Over the five-year observation period, the cities averaging the highest Livability scores were Paris, Vienna, Vancouver, Berlin, Barcelona and Amsterdam. These cities were therefore, perceived as having a competitive attractiveness advantage. However, the results of the LGC models indicated an inverse relationship between population growth and Livability, potentially creating a vicious circle whereby Livability is an important residential factor, but when causing unsustainable growth, aspects such as average house rent and price level could be negatively affected. Furthermore, it should be noted that cities with a higher Livability rating are more likely to have a below-average tourism demand, but an accelerated growth in tourism numbers over the 5-year period. This is also illustrative of the fact that urban functionalities can be deemed attractive by residents and visitors alike, potentially causing conflicts in the long run due to conflicting space demands. The magnetic effects of a livable environment, and, circularly, the pressure of population growth and tourism demand on urban livability (Law \& Buhalis, 2010; Neuman, 2005), were therefore partly established within the observational timeframe.

Environmental and sustainability concerns are high on many smart city policy agendas, and the difficult interaction between environmental scores and population numbers are evident here. There is clearly a strong interest in the environment from a residential perspective. However, there is a less unambiguous relationship between residential interests in a clean environment and the pressure population numbers place on the environment. It is found that cities with very high population numbers and an accelerated population growth perform worse on environmental indicators, because urban size exacerbates mobility and pollution problems (see, e.g., Dahmann, 1983; Gursoy \& McCleary, 2004; Pike \& Page, 2014). Curbing population growth in large cities might therefore be needed in order to increase environmental quality.

\section{Conclusion}


The different structural aspects we considered essential in order to characterize contemporary cities exert great impacts on urban attractiveness (Soteriades and Avgeli, 2007).

Our results suggest that the attractiveness of contemporary cities is at least to some extent related to the eye of the beholder, as observed in a large number of studies (e.g., Kavaratzis, 2005; Merrilees, Miller \& Herington, 2012). Aspects related to cultural dynamics (in a creative economic context) appears as a major determinant for attracting both residents and visitors, while the attractiveness for residents appear to be driven by pure economic strength (in terms of absolute growth). At the same time, the dynamics observed in research and development activities (in terms of quality of employment) seems to suggest that these are better developed in cities with a modest scope and growth. Thus, the elements more clearly oriented toward the creative aspects of contemporary economies (culture and R\&D) seem to exert higher impacts on qualitative urban attractiveness, while the overall economic dynamics fuel general population growth.

While the social aspects of sustainability considered in our study - framed within the concept of Livability (including employment, working conditions, prices and safety) - as well as the urban Environment clearly exert higher impacts on urban attractiveness, our analysis also indicates a difficult balance between Livability, Environment, and population and visitor size and growth. Specifically in terms of Livability, there is a danger of creating a perverse effect where increased Livability attracts new urbanites, which in turn negatively affects Livability. This could further be influenced by the positive effect of Livability and Cultural Interaction in attracting international visitors. Tourist numbers are further fuelled by increased accessibility, which seems to favor external visitors more than urban residents. The local population might not always favorably perceive higher tourist volumes, which is also an important matter to be addressed in the context of the massification of urban tourism.

It should also be noticed that our results are based on the identification of a general trend, based on the average performance of the cities under analysis over a 5-year period. However, each of the 40 cities considered in this study has its own deviations regarding the structural relations we have identified. Thus, although our analysis offers a comprehensive and useful assessment of the importance of the different factors influencing the performance and attractiveness of contemporary 
cities, the particular characteristics and conditions observed in each urban settlement must be carefully observed when formulating urban policies and development strategies on competitive attractiveness and destination competitiveness, as confirmed in several parts of the interpretation of our empirical results.

Finally, cities are driven by a multiplicity of preferences and interests of various stakeholders; they present many appearances and faces and are by 'no means uniform or identical' (Kourtit, 2015). There is clearly a need for an advanced geographic knowledge infrastructure for smart city policy (Laurini 2017). The new image of modern intelligent cities requires new insights and policy strategies and related smart solutions and actions in order to make the sustainable future city 'a place 4 all', including by all means residents and visitors (Kourtit, 2015). Smart city policy in a tourism context presupposes solid developmental strategies on multiple characteristics, supported by solid information systems.

\section{References}

Ahvenniemi, H., Huovila, A., Pinto-Seppä, I., \& Airaksinen, M. (2017). What are the differences between sustainable and smart cities? Cities, 60, 234-245.

Alam, S. Md., Paramati, S.R. (2016). The impact of tourism on income inequality in developing economies: Does Kuznets curve hypothesis exist? Annals of Tourism Research, 61, 111-126.

Arribas-Bel, D., Kourtit, K., \& Nijkamp, P. (2016). The sociocultural sources of urban buzz. Environment and Planning C, 34(1), 188-204.

Ashworth, G. \& Kavaratzis, M. (2009). Beyond the logo: Brand management for cities. Journal of Brand Management, 16: 520-531

Balsas, C. (2004). Measuring the Livability of an Urban Centre: An Exploratory Study of Key Performance Indicators. Planning, Practice \& Research, 19(1), 101-110.

Berrington, A., Smith, P.W.F., \& Sturgis, P. (2006). An overview of methods for the analysis of panel data. NCRM Methods Review Papers, NCRM/007, 1-57.

Bimonte, S., \& Punzo, L. (2016). Tourist development and host-guest interaction: An economic exchange theory. Annals of Tourism Research, 58, 128-139.

Boes, K., Buhalis, D., \& Inversini, A. (2016). Smart tourism destinations: Ecosystems for tourism destination competitiveness. International Journal of Tourism Cities, 2(2), 108-124.

Butler, R. (1980). The concept of a tourism area life cycle of evolution: Implications for management of resources. Canadian Geographer, 24(1), 5-12.

Butler, R. (1993). Alternative tourism: The thin edge of the wedge. In V. Smith \& W. Eadington (Eds.), Tourism Alternatives (pp. 31-46). Chichester, England: Wiley \& Sons.

Camagni, R., Capello, R., \& Caragliu, A. (2013). One or infinite optimal city sizes? In search of an equilibrium size for cities. The Annals of Regional Science, 51, 309-341.

Caragliu, A., Del Bo, C., \& Nijkamp, P. (2011). Smart cities in Europe. Journal of Urban Technology, 18(2), $65-82$.

Christaller, W. (1964). Some considerations of tourism location in Europe. Papers of the Regional Science Association, 12(1), 95-100.

Colomb, C. \& Navy, J. (2017) Protest and Resistance in the Tourist City. Routledge, London. 
Coccossis, H. (1996). Tourism and sustainability: Perspectives and implications. In G.K. Priestley, A. Edwards \& H. Coccossis (Eds.), Sustainable tourism? European experiences (pp. 1-21). Wallingford, England: CAB International.

Coccossis, H., \& Nijkamp, P. (1995). Sustainable tourism development. Aldershot, England: Avebury.

Cohen, E. (1972). Toward a sociology of international tourism. Social Research, 39, 164-182.

Curran, P.J., Obeidat, K., \& Losardo, D. (2010). Twelve frequently asked questions about growth curve modeling. Journal of Cognition and Development, 11(2), 121-136.

Currid-Halkett, E., \& Scott, A.E. (2013). The geography of celebrity and glamour: Reflections on economy, culture, and desire in the city. City, Culture and Society, 4(1), 2-11.

Dahmann, D.C. (1983). Subjective assessments of neighborhood quality by size of place. Urban Studies, 20, 3145.

De Noni, I., Orsi, L. \& Zanderighi, L. (2014). Attributes of Milan influencing city brand attractiveness. Journal of Destination Marketing \& Management, 3: 218-22.

Doxey, G. (1975). A causation theory of visitor-resident irritants: Methodology and research inferences. In Proceedings of the 6th Annual Conference of the Travel and Tourism Research Association (pp. ??-??). Whitehall, MI: Travel and Tourism Research Association.

Florida, R. (2017). Winner-take-all urbanism: Geographic divisions in the modern era. The Brown Journal of World Affairs, 23(2), 103-118.

Füller, H., \& Michel, B. (2014). 'Stop being a tourist!' New dynamics of urban tourism in Berlin-Kreuzberg. International Journal of Urban and Regional Research, 38(4), 1304-1318.

Fusco-Girard, L., \& Nijkamp, P. (2009). Cultural Tourism and Sustainable Local Development. Ashgate. Aldershot.

García, J.A., Gómez, M. \& Molina, A. (2012). A destination-branding model: An empirical analysis based on stakeholders. Tourism Management 33: 646-661.

Gursoy, D., \& McCleary, K.W. (2004). An integrative model of tourists' information search behavior. Annals of Tourism Research, 31, 353-373.

Gutiérrez, J., García-Palomares, J.C., Romanillos, G., \& Salas-Olmedo, M.H. (2017). The eruption of Airbnb in tourist cities: Comparing spatial patterns of hotels and peer-to-peer accommodation in Barcelona. Tourism Management, 62, 278-291.

Hooper, D., Coughlan, J., \& Mullen, M. (2008). Structural equation modelling: Guidelines for determining model fit. Electronic Journal of Business Research Methods, 6(1), 53-60.

Jong, M., Joss, S., Schraven, D., Zhan, C., \& Weijnen, M. (2015). Sustainable-smart-resilient-low carbon-ecoknowledge cities: Making sense of a multitude of concepts promoting sustainable urbanization. Journal of Cleaner Production, 109, 25-38.

Kashef, M. (2016). Urban livability across disciplinary and professional boundaries. Frontiers of Architectural Research, 5, 239-253.

Kavaratzis, M. (2004). From city marketing to city branding: Towards a theoretical framework for developing city brands. Journal of Place Branding, 1, 1: 58-73

Kavaratzis, M. (2005). Place Branding: A Review of Trends and Conceptual Models. The Marketing Review, 5(4): 329-342.

Kourtit, K. (2015). The 'new urban world': Economic-geographical studies on the performance of urban systems (unpublished PhD dissertation, Adam Mickiewicz University, Poznan, Poland).

Laurini, R. ((2017). Geographic Knowledge Infrastructure: Applications for Territorial Intelligence and Smart Cities. Elsevier, Amsterdam.

Law, R. (2006). Internet and tourism. Journal of Travel and Tourism Marketing, 20(1), $75-77$.

Law, R., Qi, S., \& Buhalis, D. (2010). Progress in tourism management: A review of website evaluation in tourism research. Tourism Management, 31(3), 297-313.

Lloyd, K., Fullagar, S., \& Reid, S. (2016). Where is the 'social' in constructions of 'liveability'? Exploring community, social interaction and social cohesion in changing urban environments. Urban Policy and Research, 34(4), 343-355.

Mansson, M. (2011). Mediatized tourism. Annals of Tourism Research, 38(4), 1634-1652.

Mazanek, J. (2010). Managing the heterogeneity of city tourists. In J. Manzanek \& K. Wöber (Eds.), Analysing international city tourism (pp. 81-94). Berlin, Germany: Springler-Verlag. 
Neuman, M. (2005). The compact city fallacy. Journal of Planning Education and Research, 25, 11-26.

OECD (2015) How's Life? 2015 - Measuring Well-Being. OECD Statistics Directorate. Paris.

Pike, S., \& Page, S. (2014). Destination marketing organizations and destination marketing: A narrative analysis of the literature. Tourism Management, 41, 202-227.

Riganti, P. (2009). From cultural tourism to cultural e-tourism. In L. Fusco Girard \& P. Nijkamp (Eds.), Cultural tourism and sustainable local development (pp. 263-288). Aldershot, England: Ashgate.

Romão, J., Neuts, B., Nijkamp, P., \& van Leeuwen, E.S. (2015a). Culture, product differentiation and market segmentation: A structural analysis of the motivation and satisfaction of tourists in Amsterdam. Tourism Economics, 21(3), 455-474.

Romão, J., van Leeuwen, E.S., Neuts, B., \& Nijkamp, P. (2015b). Tourist loyalty and e-services: A comparison of behavioural impacts in Leipzig and Amsterdam. Journal of Urban Technology, 22(2), 85-101.

Ruth, M., \& Franklin, R. (2014). Livability for all? Conceptual limits and practical implications. Applied Geography, 49, 18-23.

Sassen, S. (2010). The city: Its return as a lens for social theory. City, Culture and Society, 1, 3-11.

Scott, A.J. (2007). Capitalism and urbanization in a new key? The cognitive-cultural dimension. Social Forces, 85(4), 1465-1482.

Seven, H.E. (2014). Understanding cities through city brands: City branding as a social and semantic network. Cities, 38: 47-56

Sfandla, C., \& Björk, P. (2013). Tourism experience network: Co-creation of experiences in interactive processes. International Journal of Tourism Research, 15, 495-506.

Sigala, M. (2009). WEB 2.0, social marketing strategies and distribution channels for city destinations. In M. Gascó-Hernandez \& T. Torres-Coronas (Eds.), Information communication technologies and city marketing: Information opportunities for cities around the world. Hershey, PA: IGI Global.

Sigala, M., Mich, L., \& Murphy, J. (Eds.). (2008). Information and communication technologies in tourism. Heidelberg, Germany: Springer.

Soteriades, M. D., \& Avgeli, V. A. (2007). Promoting tourism destinations: A strategic marketing approach. Tourism Review, 55(3), 335-345.

Stoel, R.D., van den Wittenboer, G., \& Hox, J. (2004). Methodological issues in the application of the latent growth curve model. In K. van Montfort, J. Oud, \& A. Satorra (Eds.), Recent developments on structural equation models (pp. 241-261). Dordrecht, the Netherlands: Kluwer.

The Mori Memorial Foundation. (2012). Global power city index 2012. Tokyo, Japan: Institute for Urban Strategies, The Mori Memorial Foundation.

The Mori Memorial Foundation. (2013). Global power city index 2013. Tokyo, Japan: Institute for Urban Strategies, The Mori Memorial Foundation.

The Mori Memorial Foundation. (2014). Global power city index 2014. Tokyo, Japan: Institute for Urban Strategies, The Mori Memorial Foundation.

The Mori Memorial Foundation. (2015). Global power city index 2015. Tokyo, Japan: Institute for Urban Strategies, The Mori Memorial Foundation.

The Mori Memorial Foundation. (2016). Global power city index 2015. Tokyo, Japan: Institute for Urban Strategies, The Mori Memorial Foundation.

United Nations World Tourism Organization. (2012). Global report on city tourism. Madrid, Spain: Author.

Wall, G., \& Mathieson, A. (2006). Tourism: Change, impacts, and opportunities. New York, NY: Pearson \& Prentice Hall.

Yiannakis, A., \& Gibson, H. (1992). Roles tourists play. Annals of Tourism Research, 19(2), 287-303.

Zenker, S. (2009) Who's your target? The creative class as a target group for place branding. Journal of Place Management and Development, 2(1): 23-32.

Zenker, S., Knubben, E., \& Beckmann, S. C. (2010). Your City, My City, Their City, Our City - Different Perceptions of Place Brands by Diverse Target Groups. 6th International Conference "Thought Leaders in Brand Management". Lugano - Switzerland, April 18-20, 2010

Zenker, S., Eggers, F. \& Farsky, M. (2013). Putting a price tag on cities: Insights into the competitive environment of places. Cities 30: 133-139. 